\title{
SERVIÇO SOCIAL, FAMÍLIA E DOENÇA MENTAL INFANTO-JUVENIL EM \\ PORTUGAL
}

SOCIAL WORK, FAMILY AND A MENTAL ILLNESS IN CHILDREN AND YOUTH IN

PORTUGAL

\author{
Daniela Pinto de Almeida Leite ${ }^{1}$ \\ Helena Neves Almeida ${ }^{2}$
}

\begin{abstract}
RESUMO
O presente artigo realça a importância e premência da aposta na saúde mental da população, principalmente nos primeiros anos de vida dos indivíduos. A intervenção precoce é essencial para prevenir patologias mais graves no futuro e assim reduzir custos futuros para o indivíduo, família, sistema de saúde e até para a economia do país. Mas é sobre o «outro lado» da saúde mental que o artigo se vai debruçar primordialmente, ou seja, a família que acompanha o utente, presta cuidados, auxilia no diagnóstico e tratamento. Assim, a família sente-se sobrecarregada e a braços com uma reestruturação de papéis e expectativas familiares. Serão apontadas algumas orientações estratégicas e modalidades para a intervenção em contexto de crise familiar.
\end{abstract}

PALAVRAS-CHAVE: Serviço Social. Saúde Mental. Família. Paradigmas de Intervenção precoce

\begin{abstract}
This article enhances the importance of actuate in mental health, mainly in the infancy and youth. The early intervention is crucial to prevent severe pathologies in the future and also decrease future costs for persons, families, health systems and even for the country`s economy. However, it's about «the other face» that the article pretends look into, in other words, the family that go along with the sick person, to care of him and helps in diagnostic and treatment. So, families are overloaded and in a process of role's restructuration. It will be pointed some strategic orientations and modalities for work in a context of crisis.
\end{abstract}

KEYWORDS: Social Work. Mental Health. Family. Paradigms of intervention.

\section{NOTA INTRODUTÓRIA}

\footnotetext{
${ }^{1}$ Licenciada em Serviço Social, Faculdade de Psicologia e de Ciências da Educação, da Universidade de Coimbra. Assistente Social na Administração Regional de Saúde de Lisboa e Vale do Tejo, Agrupamento de Centros de Saúde da Amadora. Telefone: 351256412693, e-mail daniela_almeida6@hotmail.com.

${ }^{2}$ Doutorada em Serviço Social, Docente na Licenciatura em Serviço Social, Faculdade de Psicologia e Ciências da Educação, Universidade de Coimbra, Coimbra, Portugal.

Telefone: 351239 851450, e-mail hna@fpce.uc.pt.

Serv. Soc.\& Saúde, Campinas, SP v. 11, n. 2 (14) p. 287-306 jul./ dez. 2012 ISSN 1676-6806
} 
A Saúde Mental é simultaneamente um componente crucial da qualidade de vida e um requisito para a sua consolidação. Apostar na saúde mental da população é promover o bem-estar, a participação social, a formação e prevenir o estigma e exclusão social daqueles que o positivismo económico atual insiste em se esquecer de contemplar. Com efeito, a «estigmatização, a discriminação e o desrespeito dos direitos do Homem e da dignidade da pessoa doente mental continuam a ser uma realidade que se opõe aos valores europeus fundamentais» (LIVRO VERDE, 2005, p. $3^{3}$ ) e as suas incidências negativas atingem os sistemas económico, social, educativo, penal e judicial.

Porém, apesar do reconhecimento da centralidade do tema da Saúde Mental para o pleno desenvolvimento dos territórios e populações, a realidade atual apresenta-nos um cenário assombrado pelo crescimento galopante das doenças mentais na Europa. Segundo o Pacto Europeu para a Saúde Mental e Bem-Estar (2008), estima-se que quase 50 milhões de cidadãos na Europa (cerca de 11\% da população do continente) apresentem atualmente alguma forma de doença mental. A depressão confirma-se como uma das maiores preocupações ao nível da saúde pública da era moderna, pois em muitos estados membros da UE constitui o problema com maior prevalência na doença mental e em 2020 prevê-se que seja a principal causa de morbilidade nos países desenvolvidos (LIVRO VERDE, 2005). Relativamente ao suicídio, que é uma problemática associada à depressão, estatísticas realizadas na UE em 2004 referem que o número anual de mortes por esta causa ultrapassa o número de vítimas mortais de acidentes de viação, homicídio ou sida (op. cit, 2005). A cada nove minutos morre uma pessoa por suicídio na União Europeia. Ou seja, possivelmente desde o período de início da leitura deste artigo até ao seu término, a lista de suicídios na União Europeia já terá engrossado e esta situação não pode nem deve deixar-nos incólumes e indiferentes. Não negligenciando os fatores individuais da doença/perturbação mental, a organização social moderna e, em certos casos, a passividade dos órgãos de poder estão relacionados com este cenário que é co-construído e não um imperativo externo fatalista que se abate sobre nós. A um outro nível, os dados também evidenciam que a doença mental custa à UE cerca de 3\% a 4\% do PIB, sobretudo através da perda de produtividade. As doenças

\footnotetext{
${ }^{3}$ O Livro Verde é um documento elaborado pela Comissão das Comunidades Europeias que data de 2005 e que pretende apresentar o panorama actual de saúde mental dos seus Estados Membros e apontar os eixos estratégicos de intervenção nos principais domínios de acção no setor da saúde. Serv. Soc. \& Saúde, Campinas, SP v. 11, n. 2 (14) p. 287-306 jul./dez. 2012 ISSN 1676-6806
} 
mentais são uma das principais causas de reforma antecipada e de pensões por invalidez (LIVRO VERDE, 2005). Todos estes dados ilustram bem a complexidade das consequências da doença mental e a necessidade premente de uma maior intervenção neste domínio.

\section{A INTERVENÇÃO PRECOCE}

Os serviços de psiquiatria e saúde mental da infância e adolescência afirmam-se como uma das áreas chave de atuação na promoção da saúde mental. Com efeito, os pilares para uma vida com saúde mental são construídos nos primeiros anos de vida a partir dos acontecimentos marcantes, vivências pessoais e relação com os próximos. Para a Comissão Europeia (2004, cit. Comissão Nacional para a Reestruturação dos Serviços de Saúde Mental ${ }^{4}$, 2007-2016)

[...] o investimento na saúde mental das crianças e adolescentes é, pois, a acção com melhor relação custo - eficácia que pode ser tomada para contrariar o aumento contínuo dos problemas mentais em todos os grupos etários a que assistimos actualmente.

Ora, para este facto contribuem as seguintes constatações científicas: ao longo do desenvolvimento da criança é possível identificar certas fases onde determinadas perturbações mentais são mais frequentes, pelo que é possível elaborar programas de prevenção e intervenção com alguma previsibilidade; existe uma elevada continuidade entre as perturbações na primeira etapa da vida e o seu prolongamento na idade adulta, pelo que a prevenção e intervenção precoce são essenciais e a redução de custos para a saúde mental do indivíduo, família, comunidades e sistemas de saúde é significativamente menor se a atuação dos profissionais de saúde for antecipada (Comissão Nacional para a Reestruturação dos Serviços de Saúde Mental, 2007-2016).

Segundo a Academia Americana de Psiquiatria da Infância e da Adolescência (AACAP) e a Organização Mundial de Saúde - Região Europeia (OMS) uma em cada cinco crianças apresenta indícios de problemas de saúde mental e esta proporção tende a aumentar. Acresce que a maioria das crianças com perturbação psiquiátrica não recebe tratamento especializado (ANGNOLD et al. 1998; COSTELLO et al., 1996; ZWAANSWIJK et al., 2003, cit. Comissão Nacional para a Reestrutração dos Serviços

\footnotetext{
${ }^{4}$ A Comissão Nacional para a Reestruturação dos Serviços de Saúde Mental tem como principal competência a organização de um modelo administrativo de organização para o setor da saúde. Neste seguimento, a referida organização elaborou um relatório onde consta uma Proposta de Plano de Acção para a Reestruturação e Desenvolvimento dos Serviços de Saúde Mental em Portugal 2007-2016. Serv. Soc.\& Saúde, Campinas, SP v. 11, n. 2 (14) p. 287-306 jul./ dez. 2012 ISSN 1676-6806
} 
de Saúde Mental, 2007-2016). Em Portugal, não existem estudos epidemiológicos no domínio da psiquiatria infantil; no entanto, Ferreira (2006, cit. Comissão Nacional para a Reestruturação dos Serviços de Saúde Mental, 2007-2016) afirma que nos últimos anos se tem verificado um aumento de problemas acompanhado por um aumento da visibilidade social e mediática dos mesmos, o que cria uma situação de maior consciencialização social. Os maus tratos extremos, os abusos sexuais, a violência e as perturbações do comportamento em crianças cada vez mais novas, os comportamentos autoagressivos, as depressões e os comportamentos aditivos são os casos mais difundidos na sociedade.

\section{A Rede Social da Doença Mental}

Nas últimas décadas temos vindo a assistir a uma mudança de paradigma no que toca aos cuidados de saúde mental. A evolução dos psicofármacos e das técnicas terapêuticas e de reabilitação possibilitou uma maior aproximação dos centros de saúde mental à população, descentralizando-os e melhorando assim a sua acessibilidade e articulação com outros setores da saúde ${ }^{5}$. Portanto, os grandes asilos psiquiátricos que se localizavam preferencialmente longe dos grandes centros populacionais dão lugar a unidades próximas da população e estreitamente articuladas com outros níveis e setores de cuidados de saúde. Este movimento foi importante no sentido de clarear e desmistificar mitos associados à patologia mental e, de certo modo, implicar e responsabilizar a sociedade na reabilitação destas pessoas. Assim, este facto veio provocar um aumento progressivo do número de pessoas com patologia mental a viver juntamente com a sua família. Este movimento que se intensificou nos últimos trinta anos em Portugal e que é denominado de "desinstitucionalização psiquiátrica", acarretou também algumas consequências potencialmente graves para a própria família que se viu sujeita

[...] a um novo conjunto de circunstâncias, sem informação suficiente acerca da doença, com problemas na comunicação e na relação entre membros [...]. A família acaba por se sentir sobrecarregada não só com as vicissitudes da prestação informal de cuidados, como também com a responsabilidade de se constituir como o último reduto para o doente (ALMEIDA, J. et al., 2002).

\footnotetext{
${ }^{5}$ No caso do Departamento de Pedopsiquiatria e Saúde Mental Infantil e Juvenil de Coimbra optou-se pela integração do mesmo no CHC através do Decreto-lei 127/92 de 3 de Julho, de modo a propiciar uma «articulação mais eficaz das estruturas de saúde mental com outros prestadores de cuidados de saúde». Serv. Soc. \& Saúde, Campinas, SP v. 11, n. 2 (14) p. 287-306 jul./dez. 2012 ISSN 1676-6806
} 
Por outro lado, este contexto acarretou uma mais-valia: da visão da família como vilã e agente perpetuante de disfunções na criança/jovem na qual se destacaram as noções de «pais esquizofrenantes», «double-bind» e «casal sincrático passivo»; hoje opta-se pela visão da família como agente colaborador no processo de reabilitação e como sistema aberto em adaptação às novas características do familiar com perturbação mental, privilegiando a noção de «sobrecarga» familiar.

É neste contexto que a rede social assume particular relevância para o portador de distúrbio mental. No II Encontro de Serviço Social no Hospital Sobral Cid ${ }^{6}$ em 2001, Sónia Guadalupe refere quatro processos principais pelos quais as redes sociais podem favorecer a saúde dos indivíduos em níveis distintos da sua vida. São eles o facto de se constituírem como moderadoras do stress; a mobilização de mecanismos de controlo; o uso do reforço positivo dos comportamentos desejáveis por parte do portador de transtorno mental (que favorece o desenvolvimento adequado do indivíduo) e, por fim, o favorecimento de atividades pessoais que se associam positivamente com a saúde e, em última análise, com a sobrevivência do indivíduo.

O conceito de rede social que, nos últimos anos, tem merecido especial relevo na investigação científica. WELLMAN (1981, cit. GUADALUPE, 2002) define rede social através de uma metáfora curiosa e ao mesmo tempo clarificante, apresentando-a como «o conjunto de nós e laços de ligação entre os nós, em que os nós podem ser pessoas, grupos, empresas ou outras instituições». Podemos ainda distinguir a rede social pessoal que é definida como o «campo relacional de uma pessoa» (SPECK e ATTNEAVE, 1990, cit. GUADALUPE, 2002), ou seja, é o conjunto de indivíduos com quem um sujeito se relaciona, sendo essas relações percebidas como significativas para ele e diferenciadas da massa anónima da sociedade. Em suma, é o «nicho interpessoal» de cada indivíduo (SLUZKY, 1996, p. 20). Podemos ainda diferenciar a rede primária da rede secundária. No primeiro caso, encontram-se os «indivíduos que têm afinidades pessoais num quadro não institucional» (LACROIX, 1990, 2002) e no segundo caso encontra-se o «conjunto de pessoas reunidas por uma mesma função, num quadro institucionalizado de relações formais». Na intervenção social com famílias com crianças ou jovens portadores de perturbações mentais, as redes sociais secundárias são concebidas como parceiras na intervenção, através da troca de informação e pareceres, negociação, articulação e complementaridade entre estruturas. Já as redes sociais

\footnotetext{
${ }^{6}$ Hospital Psiquiátrico da cidade de Coimbra, hoje integrado no Centro Hospitalar de Coimbra. Serv. Soc.\& Saúde, Campinas, SP v. 11, n. 2 (14) p. 287-306 jul./ dez. 2012 ISSN 1676-6806
} 
primárias são sempre o motivo e objeto da intervenção.

\section{FAMÍLIA ENQUANTO CUIDADORA}

A família é inegavelmente apontada como o núcleo duro da rede primária e a célula base da sociedade, ainda que não seja o grupo exclusivo da intervenção. Ela reveste-se de uma importância ainda mais premente quando o utente é ainda criança ou jovem, pois é no espaço família que é estabelecida a primeira forma de confronto com o outro, socialização, vinculação e confiança. Na infância e adolescência, as funções afetiva, educativa e instrumental da família são ainda muito determinantes e presentes no seu desenvolvimento. Ora, como já foi referido, a família é ainda a grande prestadora de cuidados quando a criança/adolescente é portadora de perturbação mental ou sintomatologia desviante. DALE (1996) alerta para o facto de o conceito de família ser mutável e albergar um leque diversificado de interpretações e representações consoante as coordenadas espaciotemporais. Quando falamos em família, tendencialmente a nossa memória evoca a típica organização familiar europeia representada por um casal heterossexual com crianças dependentes económica, social, afetiva e instrumentalmente. No entanto, é importante evidenciar que atualmente existem cada vez mais novas formas de organização familiar caracterizadas pela monoparentalidade, reconstituição familiar onde constam também padrastos ou madrastas, adoção, coabitação com família alargada, entre outros. Tal como refere LUÍS et al. (1989, cit. FERNANDES, 2005, p. 37)

Habitualmente uma família é um pequeno grupo de pessoas ligadas por um acordo legal, sexo e/ou anos, herança, objectivo e/ou costumes e/ou crenças comuns, com o propósito de auto proteger-se, gerar e criar filhos, transmitir a cultura do subgrupo e companheirismo. Às vezes estão presentes muito poucos desses elementos e, no entanto, o grupo de pessoas envolvidas se considera como uma família.

Neste sentido, é necessário atentar às especificidades de cada família e considerar cada caso como único e diferente de todos os outros, evitando assim cair no erro da uniformização da intervenção.

A presença de uma perturbação psiquiátrica, disfunção comportamental ou escolar numa criança/adolescente é um fator associado (como antecedente ou precedente) a um certo desequilíbrio familiar. A defraudação das expectativas depositadas nos filhos, o estigma da sociedade e a maior atenção a diversos níveis que Serv. Soc. \& Saúde, Campinas, SP v. 11, n. 2 (14) p. 287-306 jul./dez. 2012 ISSN 1676-6806 
este elemento origina na família constitui um fator de ansiedade e desorganização familiar a que é necessário atentar. Por outro lado, por vezes as crianças/jovens apresentam uma sintomatologia difusa à qual não é possível atribuir um diagnóstico concreto e claro e que mais não é que uma expressão clara de um sofrimento psíquico ao qual é necessário responder precocemente sob pena de deixarmos que o quadro evolua para uma patologia cristalizada. Esta sintomatologia poderá radicar de experiências negativas e uma vinculação pobre vivenciadas no contexto de famílias disfuncionais e problemáticas. Como refere SANTOS (1991, cit. SILVA, 2001, p. 108), os «sintomas das crianças são sempre reflexo do tipo de relação que se estabelece entre elas e os adultos».

A literatura atual salienta que a família com um elemento com patologia mental é alvo de uma maior sobrecarga tanto a nível objetivo como subjetivo (BANDEIRA e BARROSO, 2005플. DALE, 1996; FAZENDA, 2008, THYER, B. e WODARSKY, J. 2007). Ao nível objetivo salientam-se as tarefas que a família tem de desempenhar tais como a procura de tratamentos, apoio financeiro e psicossocial, a diminuição das atividades de lazer ou atividades sociais, dado o tempo e o desgaste a que uma patologia mental na família apela. Já a sobrecarga subjetiva refere-se aos sentimentos que a família experimenta a partir do momento em que toma conhecimento de que o seu familiar tem uma patologia crónica. Como refere FAZENDA (2008),

[...] há um sentimento de perda em relação aos sentimentos e expectativas que se construíram acerca do seu futuro, acompanhado pela dúvida se terão sido bons pais ou se terão feito algo de errado que causou a perturbação no seu filho (ibid., p. 60).

A maior ou menor sobrecarga objetiva sentida pelos pais de crianças/adolescentes com problemas mentais, comportamentais ou escolares pode ser objetivada e detetada no relato de problemas com o sono, de limitação dos períodos de lazer, dificuldade em receber convidados em casa com receio do comportamento da criança/adolescente, negligenciar de outros familiares (frequentemente outros filhos ou o cônjuge), maior conflito intrafamiliar, entre outros. No que concerne à sobrecarga subjetiva, são de referir a sensação de esgotamento iminente, sintomatologia depressiva, desapontamento com a evolução do doente, sentimentos de culpa e somatizações.

\footnotetext{
${ }^{7}$ Segundo os autores, a sobrecarga sentida pelos familiares dos pacientes com perturbação psiquiátrica tem sido investigada por pesquisas internacionais desde meados dos anos 50 e início dos anos $6^{\circ}$ do século XX, embora o seu desenvolvimento maior tenha sido atingido em entre 1970 e 1980 . É com base nestes estudos que os autores reforçam esta posição.

Serv. Soc.\& Saúde, Campinas, SP v. 11, n. 2 (14) p. 287-306 jul./ dez. 2012 ISSN 1676-6806
} 
Segundo Bandeira e Barroso (2005), os estudos mostram consistentemente que famílias com maiores níveis de sobrecarga apresentam maiores níveis de sintomatologia depressiva e ansiedade e isto é ainda mais evidente no género feminino. Também Mcgulloway et al. (1997, BANDEIRA, BARROSO, 2004) refere que a maioria dos familiares que cuidam de doentes psiquiátricos sofre de transtornos psicológicos, em especial as mulheres.

Poder-se-á, pois afirmar que a crise familiar motivada pela ocorrência de um acontecimento angustiante (problemas de saúde mental por parte da criança/adolescente), que se transforma num fator de vulnerabilidade familiar, mina a intervenção social num departamento de pedopsiquiatria e em serviços de pedopsiquiatria em geral. Silva (2001) alerta para o facto de que o conceito de crise está banalizado na sociedade atual, transformando-o numa noção somente impregnada de negativismo. Efetivamente, o termo crise vem do grego crisia que significa «vulnerável», «momento em que uma decisão muda uma situação». Erikson (cit. SILVA, 2001) define-a como «um período crucial de vulnerabilidade acrescido de potencialidade acentuada...». Ou seja, a crise é desequilíbrio e fragilidade mas também potencialidade, criatividade e oportunidade! O surgimento e evolução da crise deriva da própria criança/adolescente e sua personalidade, das trocas e interações familiares, do contexto e dos recursos existentes e disponíveis quer sejam internos ou externos.

Neste processo, existem fatores de risco que podem propiciar e determinar a evolução do mesmo. A OMS define fatores de risco como «condições de vida de uma pessoa ou grupo que os expõem a uma maior probabilidade de desenvolver um processo mórbido ou sofrer os seus efeitos» (SILVA, 2001). Neste sentido, os principais fatores predisponentes à situação de crise familiar são a existência de doenças orgânicas ou mentais graves (para além da patologia da criança ou adolescente), existência de toxicodependência ou alcoolismo no agregado familiar, separação problemática dos pais, conflitos conjugais, grandes fratrias com parcos recursos económicos e baixo nível de diferenciação, estimulação e socialização. Ao nível extrafamiliar devemos atentar a problemas de vizinhança, subculturas de delinquência e marginalidade, deficiente cobertura de serviços de saúde, educativos e de ocupação de tempos livres e insuficiência de condições habitacionais (poucas divisões, ausência de condições de salubridade, infraestruturas, saneamento básico, ...) e precariedade económica. 
Algumas famílias nesta situação evidenciam capacidades insuspeitas de resistência perante a adversidade, força para suportar problemas complexos e capacidade de adaptação às circunstâncias de vida. A investigação científica aponta a capacidade de a família conseguir elaborar estratégias de controlo e superação da situação como um dos principais fatores suscetíveis de proteger a saúde mental dos familiares. Esta orientação estratégica é denominada por coping e refere-se ao «conjunto de estratégias intencionais utilizadas pelas pessoas para se adaptarem a circunstâncias diversas que são avaliadas como sobrecarga aos recursos pessoais» (BANDEIRA e DELL'AGLIO, cit. BANDEIRA e BARROSO, 2005, p. 40). As estratégias de coping podem ser divididas em estratégias focadas no problema a ser resolvido ou estratégias focadas na emoção sentida sobre a situação, sendo que em situações de stresse esta última tende a superar o coping focado no problema. As estatísticas também realçam que, se por um lado, os familiares mais jovens, familiares com uma menor sobrecarga e familiares com maiores índices de escolaridade tendem a desenvolver estratégias focadas no problema, por outro lado, quando existe uma maior sobrecarga familiar as estratégias baseiam-se essencialmente na restrição do convívio e participação em atividades sociais ou, no caso de maior sobrecarga subjetiva, o abuso de álcool e a procura de ajuda espiritual. Existem também alguns fatores protetores do equilíbrio familiar que interferem na perceção dos problemas e necessidades sentidos pelas famílias como variáveis moderadoras, designadamente a presença/capacidade de encontrar suporte social fornecido por familiares, amigos e colegas. Mas para além deste destaca-se ainda o bom relacionamento do casal, o grau de coesão familiar, a abertura comunicativa entre os membros do agregado, estado de saúde dos membros da família, a satisfação com a situação laboral e o acesso e mobilização de recursos materiais e simbólicos (DALE, 2007).

Tendencialmente, as famílias procuram resolver as adversidades sozinhas. Porém, nos casos em que para além dos problemas existentes subsistem também poderosas forças emocionais negativas que interagem com os comportamentos dos seus membros, estamos perante famílias disfuncionais ou multiproblemáticas que dificilmente conseguirão sair do ciclo vicioso de degradação sem ajuda profissional. Segundo SILVA (2001), perante um problema, as famílias podem reagir de duas formas diferentes: fechando-se sobre si mesmas e restringindo ao máximo qualquer comunicação com o exterior (famílias integrativas) ou, pelo contrário, investindo e interagindo primordialmente com sistemas externos e desinteressando-se da família Serv. Soc.\& Saúde, Campinas, SP v. 11, n. 2 (14) p. 287-306 jul./ dez. 2012 ISSN 1676-6806 
através do investimento em contextos diferentes (famílias centrífugas). No primeiro caso, a harmonia familiar é um valor de suma importância e que deve ser preservado através de um progressivo isolamento dos contextos de vida externos à família. No caso das famílias centrífugas há um esvaziamento dos laços emocionais e dos sentimentos partilhados através da estereotipação dos papéis intrafamiliares e da procura da supressão das necessidades emocionais em contextos externos ao sistema familiar.

\section{PERSPETIVAS DE INTERVENÇÃO SOCIAL COM FAMÍLIA(S) DE CRIANÇAS E JOVENS COM PERTURBAÇÕES MENTAIS.}

Ao intervir com a família numa situação de crise é necessário ter sempre presente a conceção de família enquanto sistema aberto em constante interação com outros sistemas e inscrita num conjunto valores, normas e padrões norteadores do seu comportamento enquanto grupo. Portanto, é necessário considerá-la como um sistema entre sistemas, o que exige o conhecimento e compreensão dos comportamentos e personalidades individuais, das relações interpessoais e das normas que regulam o dia-adia dos grupos a que os seus membros pertencem. Neste sentido, é importante refletirmos sobre três pontos essenciais: as capacidades inerentes à criança/jovem com patologia psiquiátrica e à respetiva família, a forma como as mobilizam e os recursos que a comunidade lhes pode oferecer.

A intervenção de um(a) assistente social é sempre uma mais-valia para a resolução com sucesso da situação de crise, pois ele é o interlocutor privilegiado para a informação e acesso aos recursos da comunidade bem como para a identificação dos recursos internos que as pessoas não conseguem descobrir. Ele(a) assume um olhar mais distante, racional e objetivo sobre o problema e baseia a sua ação numa relação de ajuda que tem como objetivo a autonomização e empowerment da família através da participação e partilha num processo de co construção da intervenção. Se numa conceção mais tradicional de Serviço Social, o assistente social se colocava numa posição de provedor de recursos na relação, hoje procura-se conceder esse poder ao utente e cabe àquele (a) profissional motivar, impulsionar e facilitar um processo de mudança onde o indivíduo/família tenha o papel ativo. 


\section{ESTRATÉGIAS DE INTERVENÇÃO}

Para que a intervenção do assistente social possa ser levada a cabo com sucesso, há que reconhecer que na base da relação tem que se encontrar sempre a empatia, abertura e confiança. Para que se possa estabelecer uma relação de ajuda (seja ela social, educativa ou terapêutica) com o utente (na sua dimensão individual ou coletiva) é importante demonstrar disponibilidade, encorajamento pela partilha, respeito pelos valores e prioridades da família e optar sempre pelo estabelecimento de consensos e compromissos em detrimento da ação individualista ou paternalista. Outro aspeto a considerar é a existência de emoções negativas expressas pela família caracterizadas pelo criticismo, fatalismo funcional, predominância de reforços negativos na educação das crianças/adolescentes e muito envolvimento emocional. A intervenção social não pode ficar alheia a tais sentimentos, uma vez que eles reforçam e estabelecem padrões de conduta e atitudes cristalizados, incompatíveis com a ideia de mudança.

Em situações de crise familiar, o suporte fornecido pela família, amigos e vizinhos ou pelos recursos da comunidade revela-se de extrema importância. SILVA (2001) cita algumas estratégias para identificar estas fontes de suporte, designadamente:

o reconhecimento da rede pessoal e social da família, a identificação e compreensão da forma como a família mobiliza e gere os recursos da rede familiar e social, ajuda na identificação das necessidades que a família ainda não se apercebeu, o desenvolvimento com a família de estratégias de mobilização de recursos e a promoção da capacidade para a família adquirir ou desenvolver recursos face aos problemas identificados.

No âmbito dos recursos comunitários, assiste-se a um novo movimento na sociedade contemporânea que reflete claramente alguns dos seus valores dominantes. A proliferação do surgimento de movimentos sociais e grupos de ajuda mútua e de associações de famílias é um fruto do processo de personalização exigida, onde os indivíduos se agregam segundo as suas semelhanças e interesses («grupos de iguais») de modo a reforçar o seu sentido de identidade e diferença da massa anónima (LIPOVETSKY, 1983). O seu cariz emancipatório, democrático e de cidadania participativa é inegável, constituindo um exemplo notável de envolvimento e implicação da sociedade civil na luta pelos seus direitos. O que distingue esta nova forma de agregação é o facto de serem liderados pelos seus próprios membros, afirmando-se assim, autónomos em relação aos profissionais. Nestes espaços as pessoas relativizam os problemas, partilham informação, experiências e estratégias mútuas pois vêm no outro alguém como si próprio que conhece in loco a sua realidade. Estes grupos desempenham um papel substancial na diluição do estigma e preconceito tantas vezes 
associados às doenças e na quebra do isolamento social (FAZENDA, 2008). No panorama atual português destacam-se diversas associações deste âmbito no setor da saúde mental, nomeadamente a APPACDM (Associação de Pais e Amigos do Cidadão com Deficiência Mental), a ADAP (Associação de Pais e Amigos de Deficientes Profundos), a APAD (Associação de Pais e Amigos de Disléxicos) e AMA (Associação de Amigos do Autismo), entre outras.

Para além dos grupos de ajuda mútua e associações de famílias e amigos já referidos, outras formas de apoio se começam a desenhar na rede social. São eles os gabinetes de apoio à família que frequentemente oferecem sessões de formação parental. É certo que a parentalidade é uma questão inerente à evolução humana e que as gerações anteriores sempre educaram os seus filhos sem recorrer a estes serviços. Porém, a sociedade ocidental encontra-se numa era de mutações quotidianas e bruscas, onde o stresse e a falta de tempo para os filhos teimam em assombrar o dia-a-dia dos pais.

Se é verdade que nunca em outro período da história dispusemos de tantos recursos disponíveis e de um sistema de políticas sociais que garantem elevados níveis de acessibilidade a toda a população, os momentos de crise que atravessamos abala o sistema e enfraquece o espetro de direitos conquistados durante quatro décadas após o 25 de abril de 1974. A educação permite a mudança e a liberdade e, por isso, é o meio privilegiado para a quebra dos ciclos de fatalismo funcional e social.

Independente da crise económica e social que vivemos, hoje existe uma tomada de consciência sobre a importância da educação familiar e dos ciclos educativos que se repetem de pais para filhos. Portanto, é importante dotar os adultos do agregado familiar da criança ou do jovem de competências necessárias à educação e segurança dos mesmos de modo a propiciar o seu pleno desenvolvimento. De um estádio de (in)competência inconsciente pretende-se elevar os pais a um estádio de competência consciente indo ao encontro das suas necessidades e motivações, mobilizando as suas potencialidades, propiciando a autorreflexão e o pensamento crítico. Os principais benefícios da formação parental prendem-se com a ênfase no funcionamento em rede dos serviços, a preservação da instituição familiar e da institucionalização.

A «formação de competências parentais parece constituir uma excelente oportunidade para melhorar os níveis de informação bem como as competências educativas parentais, surgindo mesmo, em vários estudos, associados a resultados bastante positivos em termos da percepção de auto eficácia, no desempenho da função parental» 
(FELDMAN, 1994; HOMBY, 1992a; WILKINSON, PARRISH \& WILSON, 1994 cit. COUTINHO, 2004, p. 57).

Salientam-se melhorias na autoconfiança e desempenho das funções maternais, no conhecimento do desenvolvimento da criança (OLSON \& BURGESS, 1997, cit. COUTINHO, 2004) e nas competências linguísticas da criança (FELDMAN, 1997; KAISER, HANCOCK \& HESTER, 1998, cit. COUTINHO, 2004).

Face à complexidade dos contextos, das problemáticas associadas e seu impacto na dinâmica e funcionamento das famílias, impõe-se um novo paradigma de intervenção no domínio da Saúde Mental Infanto-Juvenil. Uma intervenção alicerçada no princípio da participação ativa, como um direito de cidadania, e na construção de alternativas sociais, que podem passar pela intervenção direta com as famílias e com as crianças e os jovens (até aos 18 anos), mas que não pode negligenciar um trabalho comprometido com a mudança social.

Como salienta CABRAL (2011) "A intervenção social, neste contexto, organizase particularmente na interacção dos sistemas terapêutico, familiar e escolar". O pedido/problema pode ser apresentado pela família, pelo doente, pela comunidade (por exemplo, a escola) ou por um elemento da equipa terapêutica (geralmente um pedopsiquiatra ou dos cuidados primários de saúde). São avaliados os fatores de risco e os fatores protetores do doente e da família, bem como as problemáticas potencialmente associadas que ocorrem nos sistemas familiar e escolar, e que podem ser de natureza diversa: Problema social ou de saúde específico, em um ou ambos os progenitores: alcoolismo, dependências químicas e doença crónica grave; Relações intrafamiliares: desestruturação das relações intrafamiliares, onde se destacam conflitos permanentes e indiferenciação de subsistemas; Práticas educativas parentais: castigos inadequados, a superprotecção ou o abandono; Precariedade económica e social (desemprego, baixos rendimentos, falta de condições habitacionais); Relação entre os sistemas escolar $e$ familiar: dificuldades na relação pais-professores; Relações em contexto escolar: dificuldades na relação professores-alunos; relação entre pares (descriminação, Bullying, ...), insucesso escolar.

É o diagnóstico social, designadamente a natureza das problemáticas associadas, que interfere na orientação e delimitação das ações profissionais, e que oscilam entre a intervenção social e terapêutica, mediação social, escolar e comunitária. Não se trata apenas de apoiar os pais na resolução dos problemas identificados, nem de prestar 
acompanhamento psicossocial à família integrá-la num processo de mediação familiar. Supera-se a dimensão interindividual na regulação dos conflitos, por que eles em última análise produzem efeito na forma como os diversos sistemas se articulam, na forma como se produzem e se cortam os laços sociais, no processo de desenvolvimento pessoal e social local. É nessa sinergia que se tem de intervir como forma preventiva, protetora e promotora de mudanças e transformações sociais.

Como salienta ALVES (2001, p. 187) a intervenção do assistente social na área da Saúde Mental Infantil e Juvenil é um processo relacional e dinâmico que se desenvolve ao longo do tempo.

LEITE (2010) especificou algumas das características dessa intervenção social a nível micro (o menor ${ }^{8}$ e a família), e a nível meso (o trabalho/emprego e a escola) (ver figura 1). A estes acrescentamos o nível macro, uma brecha para ultrapassar a perspectiva executiva, tecnicista e pragmática que se mantém associada ao perfil dos assistentes sociais.

\footnotetext{
${ }^{8}$ De acordo com a Lei n. ${ }^{\circ}$ 147/99, de 1 de Setembro - Lei de protecção de crianças e jovens em perigo, o termo menor foi substituído pela expressão "crianças e jovens" respetivamente com idade inferior a 18 e a 21 anos. No entanto o uso do termo "menor" ainda é corrente em documentos profissionais. Serv. Soc. \& Saúde, Campinas, SP v. 11, n. 2 (14) p. 287-306 jul./dez. 2012 ISSN 1676-6806
} 
Figura 1 - Proposta para a construção de um novo paradigma de intervenção em Saúde Mental Infanto-Juvenil em Portugal (LEITE, 2010)

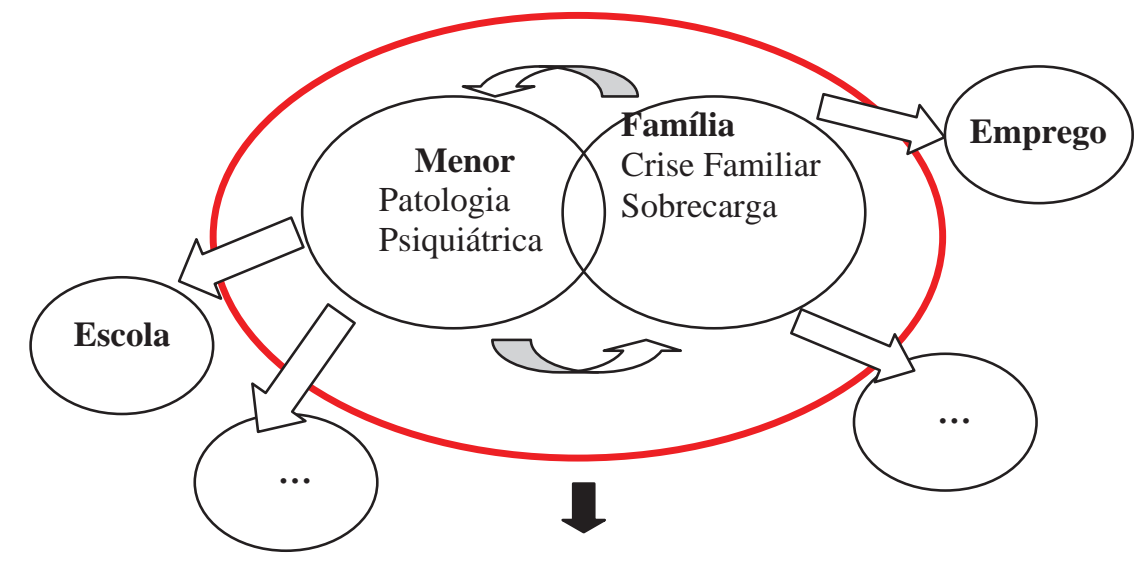

CARACTERÍSTICAS ESPECÍFICAS DA INTERVENÇÃO SOCIAL

\section{SERVIÇO SOCIAL COM FAMÍLIAS EM SAÚDE MENTAL INFANTIL E JUVENIL}

Contributo: No domínio da pedopsiquiatria, a intervenção social oferece um olhar pluridimensional e privilegiador dos elos de ligação entre os indivíduos e grupos. Procura recursos internos e externos à família com o intuito de promover o empowerment e o bemestar.

\section{Pressupostos:}

- Empatia;

- Abertura;

- Disponibilidade;

- Encorajamento da partilha;

- Respeito pelos valores e prioridades da família;

- Estabelecimento de consensos em detrimento da acção individualista ou paternalista.

\section{Estratégias:}

- Conhecimento da rede pessoal e social da família;

- Identificação e compreensão da forma como a família mobiliza e gere os recursos da rede familiar e social;

- Ajuda na identificação das necessidades;

- Desenvolvimento com a família de estratégias de mobilização de recursos;

- Promoção da capacidade para a família adquirir ou desenvolver recursos.

\section{Novas Orientações:}

- Grupos de Ajuda Mútua/Associações de Famílias ou Amigos

- Gabinetes de Apoio à Família (Cursos de Formação Parental) ～LEITE, D. (2010, p. 43) 
Bronfenbrenner (1996) é extremamente importante na análise da intervenção em contexto de complexidade a nível pessoal e social, na medida em que nega o modelo de deficit e introduz uma dinâmica multipolar:

1 - a intervenção a nível micro, com indivíduos e rede primárias de suporte (família, amigos, vizinhos) no sentido de garantir o direito ao apoio social e ao aumento do poder de tomada de decisão a nível individual e familiar;

2 - a nível meso (de articulação inter e intrainstitucional) como condição de adequação da oferta à procura social;

3 - a nível macro, mais abrangente e focalizado na avaliação das políticas públicas e na criação de estruturas de oportunidade.

Como refere ALMEIDA (2001, 2004), o papel essencial do Serviço Social reside no (re)cerzimento e reconfiguração de laços sociais, identitários da mediação social transformadora que opera. Este é um desafio que se coloca à profissão, em contextos complexos e multidisciplinares.

\section{CONSIDERAÇÕES FINAIS}

A redefinição do espaço e estatuto dos centros de saúde mental que privilegia a proximidade à população e a intersetorialidade com outros serviços foi o principiar de uma longa caminhada que ainda não chegou ao seu término. A aposta na família que é o principal cuidador e, se quisermos, a «psiquiatra de primeira linha», é fulcral para conseguirmos o pleno desenvolvimento da criança. No entanto, a realidade deixa antever que a família está sobrecarregada e minada pela crise em diversos aspetos, pois encontra-se desacreditada nas suas capacidades e desapoiada em termos de redes sociais.

É neste contexto que o Serviço Social tem de atuar, ultrapassando a adoção de posturas de intervenção uniformizadas, pois cada família é única e possui os seus próprios contextos, tempos, recursos e dinâmicas. Impõe-se a reflexão crítica no quotidiano do assistente social pelo que é necessário reinventar constantemente a prática de modo a adaptá-la ao contexto de intervenção. Atualmente, começam a afirmar-se algumas formas de intervenção importantes para as famílias que têm menores com perturbação mental, tais como movimentos sociais e associações de ajuda mútua, com investimento na formação parental, que merece destaque e atenção por parte do Serviço Social, devido aos resultados consideráveis obtidos na melhoria das dinâmicas Serv. Soc. \& Saúde, Campinas, SP v. 11, n. 2 (14) p. 287-306 jul./dez. 2012 ISSN 1676-6806 
familiares e na confiança e empowerment da própria família. Mas é preciso ir mais longe, num percurso de afirmação da área científica de Serviço Social na investigação, planeamento e avaliação, pela proximidade que mantém com as realidades e dinâmicas interindividuais, sociais e políticas.

\section{REFERÊNCIAS}

ALMEIDA, H. Conceptions et Pratiques de la Médiation Sociale. Les modèles de médiation dans le quotidien professionnel des assistants sociau. Coimbra: Fundação Bissaya-Barreto/Instituto Superior Bissaya-Barreto, 2001.

ALMEIDA, H, A recomposição dos laços sociais - uma mediação expressiva e instrumental na luta contra a exclusão social. In: CUNHA, Pedro (Org.). Mediação, uma forma de resolução alternativa de conflitos. Porto: Edições Universidade Fernando Pessoa, 2004, p. 33-61.

ALMEIDA, J. et al. Questionário de Problemas Familiares: Desenvolvimento da Versão Portuguesa de Um Instrumento de Avaliação da Sobrecarga Familiar. Psicologia, Saúde \& Doenças, Lisboa, n. 3, p 165-177, 2002.

ALVES, F. Acção Social na Área da Saúde Mental, Universidade Aberta, Lisboa, 2001.

BANDEIRA, M., BARROSO, S. Sobrecarga das famílias de pacientes psiquiátricos. Jornal Brasileiro de Psiquiatria, Rio de Janeiro, n. 54, p. 22- 29, 2005.

BRONFENBRENNER, U. A Ecologia do Desenvolvimento Humano: Experimentos Naturais e Planejados. Porto Alegre: Artes Médicas, 1996.

CAMPOS, P., SOARES, C. Representação da sobrecarga familiar e adesão aos serviços alternativos em saúde mental. Psicologia em Revista, Belo Horizonte, n. 11, p. 219-37, 2005.

COUTINHO, M. Apoio à Família e Formação Parental. Revista Análise Psicológica, Lisboa, n. 1, p. 55-64, 2004.

DALE, N. Working with families of children with special needs: partnership and practice. Londres: Routledge, 1996.

FAZENDA, I. O puzzle desmanchado: saúde mental, contexto social, reabilitação e cidadania. Lisboa: Climepsi Editores, 2008. 
FERNANDES, N. A doença mental e a sobrecarga dos familiares. 2005, 70 F. Relatório de Estágio em Serviço Social, Ramo de Saúde. Instituto Superior Miguel Torga, Coimbra

GARRET, C. et al. Questionário de Avaliação da Sobrecarga do Cuidador Informal (QASCI) - Reavaliação das propriedades psicométricas. Revista Referência, Porto, n. 11, p. 17-31, 2004.

HOGHUGHI, M., LONG, N. Handbook of parenting: theory and research for practice. Londres: Sage, 2004.

LEITE, D. Ver Para Além do Visível: a Perturbação Mental na Criança/Adolescente no seio da Família. 2010, 92 F. Relatório de Estágio em Serviço Social - Universidade de Coimbra, Faculdade de Psicologia e de Ciências da Educação, Coimbra.

LIPOVETSKY, G. A Era do Vazio. Ensaio sobre o Individualismo Contemporâneo. Lisboa: Relógio de Água, 1983.

MENDONÇA, M. Mais Vale Prevenir... Memórias de uma época e de um contributo para a saúde mental infantil. Coimbra: Edições Minerva, 2002.

SILVA, L. Acção Social na Área da Família. Lisboa: Universidade Aberta, 2001.

THYER, B., WODARSKY, J. Social work in mental health: an-evidence based approach. Hoboken: Routledge, 2007.

\section{FONTES ELECTRÓNICAS}

CABRAL, I. Serviço Social na Saúde Mental infantil e juvenil. 2011. Disponível em: http://servicosocialsaude.wordpress.com/saudementalinfantil/. Acesso em 23 outubro 2014.

COMISSÃO DAS COMUNIDADES EUROPEIAS. Comissão das Comunidades Europeias. Livro Verde: Melhorar a Saúde Mental da população. Rumo a uma estratégia de Saúde Mental na União Europeia. Disponível em: <http://eurlex.europa.eu/LexUriServ/site/pt/com/2005/com2005_0484pt01.pdf>. Acesso em 12 de Set. 2009

COMISSÃO EUROPEIA. Pacto Europeu para a Saúde Mental e Bem-estar. Disponível em: $\quad$ <http://www.minsaude.pt/NR/rdonlyres/A6AA36F1-1002-4E80-9E7A44C1AA016CD5/0/pactoeuropeusaudemental.pdf>. Acesso em 12 de Set. 2009 
COMISSÃO PARA A REESTRUTURAÇÃO DOS SERVIÇOS DE SAÚDE MENTAL. (2007-2016). Proposta do plano de acção para a reestruturação e desenvolvimento dos serviços de saúde mental em Portugal. Disponível em <http://www.acs.minsaude.pt/wpcontent/uploads/2008/01/relatorioplanoaccaoservicossa udemental.pdf>. Acesso em 12 Set. 2009

DELGADO, G. Reinventar a intervenção em famílias multiproblemáticas: Formação Parental. $\quad$ Disponível em $<$ http://www.gaf.pt/jornadas/xiv_jornadas/resumos/4.pdf> $>$. Acesso em 4 de Nov. 2009 DIRECÇÃO GERAL DE SAUDE. Rede de Referenciação de Psiquiatria e Saúde Mental. Disponível em http://www.dgs.pt/upload/membro.id/ficheiros/i007439.pd. Acesso em 12 de Set. de 2009

GUADALUPE, S. Intervenção em Rede e Doença Mental. In: II Encontro de Serviço Social em Saúde Mental: Novas Perspectivas, 2001, Coimbra. Anais electrónicos... Coimbra, 2001. Disponível em: http://www.cpihts.com/PDF03/Sonia\%20Guadalupe.pdf. Acesso em 26 de Out. 2009

SILVA, R., WITIUK, I. Família do Portador de Transtorno Mental: Vítima ou Vilã? Disponível em < http://www.cpihts.com >. Acesso em 16 de Out. 2009 SILVA, R., WITIUK, I. Dificuldades para a Implantação do Processo de (Des)Hospitalização do Portador de Transtorno Mental. Disponível em: http://www.cpihts.com/2003_07_06/Ilda_lopes.htm. Acesso em 16 de Out. de 2009

\section{LEGISLAÇÃO}

PORTUGAL. Decreto-lei $\mathbf{n}^{\mathbf{0}}$ 127/92 de 3 de Julho. Diário da República - I Série. Ministério da Saúde.

PORTUGAL. Lei n⿳0 36/98 de 24 de Julho. Diário da República - I Série. Ministério da Saúde

PORTUGAL. Lei n. ${ }^{\circ}$ 147/99, de 1 de Setembro. Diário da República - I Série. Ministério da Justiça 
